\title{
CFD- МОДЕЛИРОВАНИЕ СОПРЯЖЕННОГО ТЕПЛОВЛАГОПЕРЕНОСА МЕЖДУ ПОРИСТЫМИ СТРОИТЕЛЬНЫМИ МАТЕРИАЛАМИ И ПАРОВОЗДУШНОЙ СРЕДОЙ
}

Круковский П.Г., доктор техн. наук, Полубинский А.С., канд. физ-мат. наук, Тадля О.Ю., канд. техн. наук, Коваленко В.Н., канд. техн. наук Інститут технічної теплофізики НАН Украӥни, вул. Желябова, 2, а, Київ, 03680, Украӥна

Розроблена CFD-модель в програмному середовищі ANSYSFLUENT для моделювання спряженого тепловологопереносу між твердою поверхнею огородження приміщення i пароповітряним середовищем прошарку 3 урахуванням радіаційного та конвективного теплообміну. Спряжений тепловологоперенос реалізований за допомогою спеціально створених функцій, що розширело розрахункові можливості програми ANSYSFLUENT. Отримані розподіли температур та абсолютних вологостей в огороджуючій конструкції 3 достатньою точністю співпадають 3 експериментальними даними.
Разработана CFD-модель в программной среде ANSYS-FLUENT для моделирования сопряженного тепловлагопереноса между твердой поверхностью ограждения помещения и паровоздушной средой прослойки с учетом радиационного и конвективного теплообмена. Сопряженный тепловлагоперенос реализован с помощью специально созданных функций, что расширило расчетные возможности программі ANSYS-FLUENT. Полученные распределения температур и абсолютных влажностей в ограждающей конструкции с достаточной точностью совпадают с экспериментальными данными.
A CFD-model to simulate the conjugate heat and moisture transfer between the building envelope surface and internal air-steam-medium layer with radiation and convective heat transfer. was developed with ANSYS-FLUENT software. The conjugate heat and moisture transfer is realized using of specially created function, that expanded calculated capabilities of ANSYS-FLUENT software. Obtained temperature and absolute humidity distributions with sufficient accuracy correspond to the experimental data.

Библ. 10, рис. 2, табл. 1 .

Ключевые слова: пористый строительный материал, тепловлагоперенос, CFD-моделирование.

$a$ - соотношение между влагосодержанием и абсолютной влажностью согласно кривой сорбции для данного материала;

$D$ - коэффициент диффузии пара в воздухе, $\mathrm{m}^{2} / \mathrm{c}$;

$D_{w}$ - влагопроницаемость (агрегатное состояние - вода) в материале, кг/(м·c·\%);

$H$ - энтальпия, кДж/кг;

$h_{v}$ - теплота парообразования, $2,5 \cdot 10^{6}$ Дж/кг;

$k^{v}-$ степень интенсивности поглощения (либо

выделения) влаги из пара паровоздушной смеси, кг/(м.С·Па) ;

$m$ - концентрация (доля паров воды во влажном воздухе), кг/кг;

$p$ - парциальное давление, Па;

$P_{s}$ - статическое давление, Па;

Совместные расчеты теплового и влажностного состояния помещения и ограждающих
$S_{m}$ - источник массы, кг/(м².c);

$v$ - скорость, $\mathrm{M} / \mathrm{c}$;

$w$ - влагосодержание в материале, кг/кг;

$x$ - координата, м;

$y$ - координата, м;

$\lambda_{\mathrm{w}}$ - теплопроводность влажного материала, $\mathrm{BT} / \quad(\mathrm{M} \cdot \mathrm{C})$;

$\rho-$ плотность, кг $/ \mathrm{M}^{3}$;

$\tau-$ время, с.

Нижние индексы:

$m$ - масса;

$s$ - статическое;

$v$ - параметр относится к пару;

$w$ - параметр относится к влаге.

конструкций позволяют избежать нарушения комфортных условий человека в помещении, 
образования зон с повышенной влажностью на поверхности или внутри ограждающих конструкций и ухудшения их теплозащитных свойств.

Поскольку здания представляют собой сложные системы, они могут быть изучены на различных уровнях (здание в целом, отдельные помещения, типичные строительных конструкции и строительные материалы). В зависимости от поставленной цели и дальнейшего применения, процессы тепло-, воздухо- и влагопереноса в зданиях моделируются с помощью различных подходов и математических моделей, которые активно разрабатываются в настоящее время.

Сложность математического описания процессов влагообмена в ограждающих конструкциях помещений обусловлена множеством факторов. Это и составной характер ограждающих конструкций, переменность граничных условий как снаружи помещения, так и внутри его, неизотермичность и нестационарность процессов во времени, изменение агрегатного состояния влаги, которая находится в ограждении, нелинейность расчетных характеристик и т.д. Сложность также заключается в том, что некоторые, широко распространенные компьютерные программы, не имеют возможности решать определенные задачи, либо требуются дополнительные усилия со стороны пользователей. Например, в программе ANSYS-FLUENT [1] подобной проблемой является решение задач сопряженного тепловлагопереноса через конструкции, когда необходимо учесть как перенос влаги в самом материале конструкции, так и радиационный и конвективный перенос во влажном воздухе, в котором находится данная конструкция (например, помещение или воздушная прослойка). Проблема состоит в том, что для радиационного теплообмена на твердых поверхностях необходимо наличие непроницаемой стенки, однако в таком случае невозможно решать задачу переноса массы через такую поверхность.

Для решения этой проблемы в [2] в среде программы ANSYS-FLUENT предложено использовать совместное решение CFD-модели помещения и упрощенной влажностной моде- ли ограждения в постановке с сосредоточенными параметрами. В модели с сосредоточенными параметрами рассчитывается коэффициент массоотдачи и влагосодержание (массовая доля пара) на каждом шаге по времени для использования в расчете CFD-модели. Влагосодержание в граничных ячейках воздуха представляется как поток влаги через границу области решения «воздух помещения - ограждение» с помощью «User Defined Scalar» (UDS) [1], который использует это значение как граничное условие. Вычисления для накопления влаги в стенке выполняются в конце каждого временного шага расчета CFD-модели для теплового состояния и движения воздуха помещения. Этот подход реализован с помощью «User defined function» (UDF) [1], которая определяет плотность влажного воздуха и коэффициент диффузии в модели. Т.о., на каждом шаге по времени две модели обмениваются результатами расчетов. По мнению авторов, такое взаимодействие позволяет не только получать полную картину теплового и влажностного полей в воздухе помещения, но и с небольшими усложнениями модели учитывать влияние влажностного состояния ограждений помещения на влажностное состояние воздуха с достаточной точностью. Недостатком этого подхода является допущение изотермичности рассматриваемой поверхности пористой строительной конструкции, через которую идет тепловлагоперенос, что в реальности встречается редко. В [3] ограждающие конструкции помещения представлены в виде неподвижной жидкости с соответствующими свойствами материалов. Диффузионная модель в стене имеет два значения влагосодержания на противоположных границах конструкции, а внутри стены предполагается линейное распределение влагосодержания между этими граничными значениями. Для моделирования влагообмена между двумя жидкостями (воздухом и стеной) авторам пришлось задать непроницаемую стенку, - барьер, который позволяет им взаимодействовать с помощью специальных функций. Этот барьер разделен на две половины: с одной стороны он контактирует с воздухом, с другой - со стенкой. Обе стороны имеют одни и те же геометрические координаты. Таким образом, 
авторы создали функцию, которая переносит массовый поток влаги через границу с помощью функций, обеспечивающих влагообмен между ячейками по обе стороны этого барьера. Однако, авторы указывают на то, что данный подход нуждается в проверке на натурном эксперименте, который позволит учесть нестационарность процессов тепловлагопереноса и радиационный теплообмен между поверхностями ограждений помещения.

Для обеспечения получения адекватных результатов важно, чтобы все входные параметры (т.е. граничные условия, свойства материалов и т.д.) были хорошо известны или измерены и чтобы влияние неконтролируемых факторов было сведено к минимуму. Это часто невозможно в случае с натурными измерениями, где многие внешние воздействия неизвестны или трудно измеряемы. Поэтому большинство экспериментальной работы по изучению процессов влагопереноса выполняется в хорошо контролируемых условиях, то есть в климатиче-

$$
\begin{aligned}
& \frac{\partial w}{\partial \tau}=\frac{\partial}{\partial x}\left[D_{w} \frac{\partial w}{\partial x}\right]+\frac{\partial}{\partial y}\left[D_{w} \frac{\partial w}{\partial y}\right]+\frac{\partial}{\partial x}\left[k \cdot(a \cdot m-(w+m)) \frac{\partial P}{\partial x}\right]+\frac{\partial}{\partial y}\left[k \cdot(a \cdot m-(w+m)) \frac{\partial P}{\partial y}\right] \\
& \frac{\partial H}{\partial \tau}=\frac{\partial}{\partial x}\left[\lambda_{w} \frac{\partial T}{\partial x}\right]+\frac{\partial}{\partial y}\left[\lambda_{w} \frac{\partial T}{\partial y}\right]+h_{v} \frac{\partial}{\partial x}\left[k \cdot(a \cdot m-(w+m)) \frac{\partial P}{\partial x}\right]+h_{v} \frac{\partial}{\partial y}\left[k \cdot(a \cdot m-(w+m)) \frac{\partial P}{\partial y}\right] \\
& \frac{\partial m}{\partial \tau}=\frac{\partial}{\partial x}\left[D \frac{\partial m}{\partial x}\right]+\frac{\partial}{\partial y}\left[D \frac{\partial m}{\partial y}\right]-\frac{\partial}{\partial x}\left[k \cdot(a \cdot m-(w+m)) \frac{\partial P}{\partial x}\right]+\frac{\partial}{\partial y}\left[k \cdot(a \cdot m-(w+m)) \frac{\partial P}{\partial y}\right]
\end{aligned}
$$$$
\frac{\partial \mathrm{P}_{\mathrm{s}}}{\partial \tau}+\frac{\partial}{\partial \mathrm{x}}(\rho \cdot \mathrm{v})+\frac{\partial}{\partial \mathrm{y}}(\rho \cdot \mathrm{v})=\mathrm{S}_{\mathrm{m}} \text {; }
$$$$
\frac{\partial}{\partial \tau}(\rho \cdot v)+\frac{\partial}{\partial x}(\rho \cdot v)+\frac{\partial}{\partial y}(\rho \cdot v)=-\frac{\partial}{\partial x} P_{s}-\frac{\partial}{\partial y} P_{s} .
$$

Уравнение (1) описывает влагоперенос в материале ограждающей конструкции с учетом перехода части пара из паровоздушной смеси во влагу. (2) - передачу теплоты в материале с учетом изменения его влажности, (3) -диффузию пара в паровоздушной смеси и уход части пара во влагу материала, (4) и (5) представляют собой уравнение неразрывности и движения. В пористой среде переход из пара во влагу и обратно, предложенный авторами, учитывается третьим и четвертым слагаемыми в правых частях уравнений (1)-(3). Модель (1)-(5) описывает как процесс отдачи пара паровоздушной смесью в строитель- ских камерах или на специально построенном испытательном оборудовании.

Однако, как указано в [4], не всегда экспериментальные исследования в климатических камерах на образцах уменьшенного размера могут правильно описывать влажностные процессы, происходящие в ограждающих конструкциях помещений реальных размеров. Отмечено, что распределение относительной влажности в помещении может значительно меняться вдоль внутренних поверхностей, что влияет на передачу влаги от воздуха в помещении к материалу поверхности ограждения, и это не дает возможности правильно оценить накопление влаги поверхностями ограждающих конструкций.

Разработка модели тепловлагопереноса в материале в сопряженной постановке с влажным воздухом около его поверхности и ее проверка на образце газобетона приведена детально в [5]. Двухмерная модель описана системой следующих уравнений:

ный пористый материал ограждающей конструкции, который увлажняется, так и наоборот. Паропроницаемость в материале в уравнениях (1)-(3) учитывается выражением $k \cdot(a \cdot m-(w+m))$, где коэффициент $a$ вычисляется из кривой сорбции материала и является функцией влагосодержания и абсолютной влажности. В стационарном режиме, $a \cdot m=(w+m)$, т.е. отсутствует приток влаги и пара в материал, что является физичным для этого режима.

Разработанная модель сопряженного тепло- и массопереноса в строительном материале была опробована при моделировании процесса 
увлажнения блока газобетона в лабораторных изотермических условиях, и показала достаточное совпадение расчетных результатов и экспериментальных данных [5]. Однако, в естественных условиях увлажнения ограждающих конструкций здания массоперенос всегда сопровождают конвективные и радиационные потоки тепла, которые оказывают значительное влияние.

Проверить работоспособность предложенной модели в программе ANSYS-FLUENT на реальной ограждающей конструкции в натурных условиях и является целью настоящей рабоmbl.

Предложенная модель позволит выполнять правильный учет особенностей сопряженного тепло- и массопереноса в ANSYS-FLUENT с учетом радиационного и конвективного теплообмена и проверить это моделированием реальной ограждающей конструкция в естественных условиях. Верификация модели проведена путем моделирования сопряженного тепло- и массопереноса через наружную ограждающую конструкцию экспериментального дома в г. Гренобль [6].

Для достижения поставленной цели были выполнены следующие работы:

1. Создание модели тепловлажностного состояния наружной ограждающей конструкции исследуемого дома, представляющей собой многослойную пористую стенку и воздушную прослойку между стенкой и наружным покрытиeм;

2. Сравнение результатов расчетов с имеющейся экспериментальной информацией.

Ниже приведено описание экспериментальных исследований объекта в естественных условиях. Целью исследований, изложенных в [6-8], было изучение недопущения конденсации влаги в домах с многослойными ограждениями из дерева с утеплением из целлюлозной ваты. Экспериментальные исследования проводились в г. Гренобле, Франция в феврале 2012 года в деревянном доме $20 \mathrm{M}^{3}$ (размеры 4.56×4.55×2.41м) c многослойными наружными ограждениями (конструкция стены представлена на рис. 1).

Температура воздуха в помещении экспериментального дома поддерживалась системой отопления на уровне $20{ }^{\circ} \mathrm{C}$. Температура окружающей среды оставалась отрицательной все время проведения эксперимента, солнечная радиация измерялась на восточной и южной стороне дома и достигала 600 Вт/м². В доме была оборудована система вентиляции, кратность воздухообмена оценивалась на уровне 0,14 1/час.
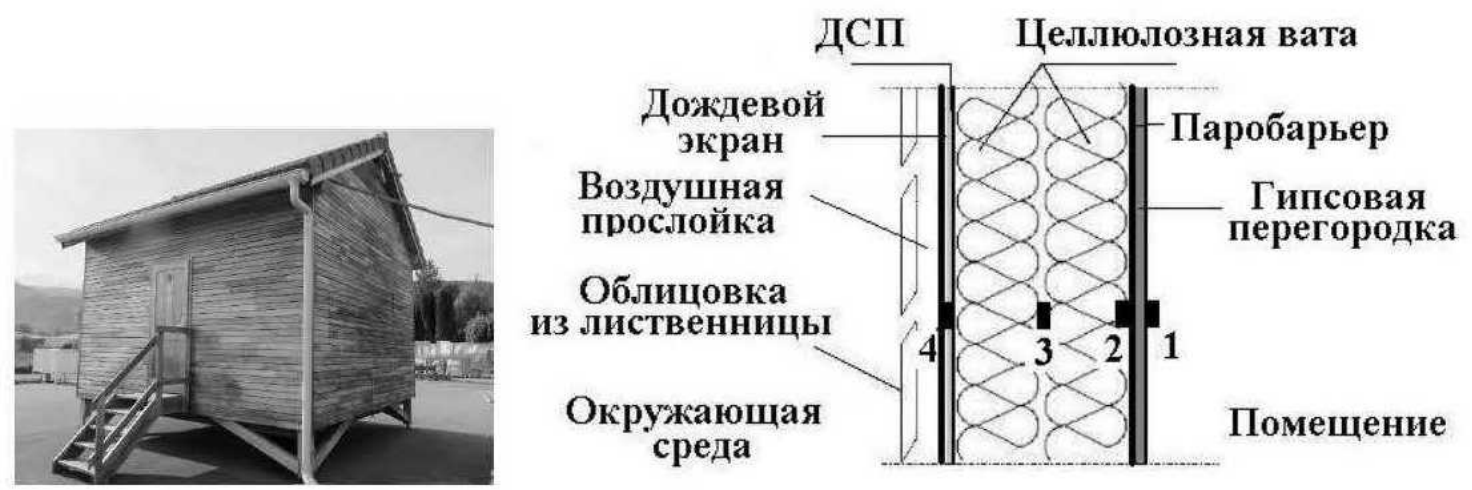

Рис. 1. Фото экспериментального дома слева, и многослойная конструкция стены справа [6]. Цифрами показаны номера датчиков влажности и температуры.

Для уменьшения влияния теплопотерь в грунт на тепловое состояние наружных ограждений, пол дома был поднят на 0,57 м над уровнем земли и тщательно изолирован. В структуре ограждающей конструкции внутренний слой паробарьера (рис. 1) обладает свойством полной непроницаемости для пара и воды, а наружный дождевой экран не может пропускать воду, но может пропускать пар из окружающей среды. Скорость восходящего конвективного потока в воздушной прослойке принята $0,5 \mathrm{~m} / \mathrm{c}$ и его течение ламинарное (согласно данным [6]). Стены дома были оснащены термогидрометрами по толщине конструкции и датчиками теплового 
потока. Кроме исследования непосредственно теплового и влажностного режима дома, проводились многочисленные исследования паропроницаемости материалов, используемых в ограждающих конструкциях, влияния вентиляции на влажностный режим помещения и т.д. Более детально исходные данные, процесс проведения эксперимента, используемое оборудование описано в [6-8]. Изотермы сорбции материалов стен, используемых в экспериментальном доме, приведены в [9].

Экспериментальные исследования проводились следующим образом. На протяжении трех месяцев до начала проведения эксперимента поддерживались постоянные тепловые и влажностные условия в доме. Количество пара, выделяемое внутри помещения от парогенератора (генератора холодного тумана), равнялось 200 г/час, влаговыделение происходило на протяжении 28 часов. Общее количество воды, испаренное из парогенератора, равнялось 6 кг. Система вентиляции дома была выключена на весь период проведения эксперимента, однако вентиляционное отверстие в наружной стене не было закрыто.

Физическая модель процессов тепломассопереноса через многослойную конструкцию с вентилируемым фасадом следующая. Из-за разницы температур воздуха и относительных влажностей в помещении и окружающей среде возникают потоки пара и влаги, которые движутся сквозь ограждающую конструкцию в направлении помещения. Навстречу им двигается поток влаги из помещения. Влага, выделяющаяся в помещении парогенератором, конденсируется на внутренней поверхности гипсовой перегородки и проникает вглубь ее. Паробарьер, установленный за слоем гипса, должен обеспечить непроницаемость для пара и влаги, чтобы целлюлозная вата (материал утеплитель этой конструкции) не увлажнился. Т.к. увлажнение слоя утеплителя увеличит теплопроводность целлюлозной ваты и всей конструкции в целом и может привести к образованию зоны, где будет накапливаться конденсат. В условиях отрицательных температур окружающей среды накопленная влага может превратиться в лед. При повышении температуры образовавшийся лед может таять, и такой процесс может периодически происходить и разрушать материал утеплителя. Со стороны окружающей среды проникновению внутрь конструкции влаги, но не пара мешает дождевой экран, установленный перед слоем ДСП. Пар может проникать в слой утеплителя. Природный вентилируемый фасад и облицовка из лиственницы снижает воздействие солнечной радиации и дождя на многослойную конструкцию. В воздушной прослойке фасада движется поток воздуха вертикально вверх и обеспечивает конвективный перенос тепла между поверхностями облицовки и ДСП. Из-за разницы температурнаповерхностях облицовки и ДСПвозникает радиационный теплообмен, который может быть днем направлен в сторону помещения, а ночью - в обратную сторону.

Компьютерная двухмерная модель ограждения помещения (1)-(5) создавалась в программе ANSYS-FLUENT. В модели рассматриваются следующие физические процессы:

1. сопряженный конвективный теплообмен в воздушной прослойке ограждения;

2. радиационный теплообмен в воздушной прослойке ограждения (между поверхностями облицовки и ДСП);

3. сопряженный тепловлагообмен в воздушной прослойке ограждения;

4. теплоперенос внутри ограждающих конструкций;

5. паро- и влагоперенос внутри ограждающих конструкций;

6. влияние падающей солнечной радиации на наружную поверхность ограждения (через коэффициент $\alpha_{\text {рад) }}$;

7. движение воздуха в воздушной прослойке ограждения.

Принципы реализации физической модели в программе ANSYS-FLUENT:

1). ограждающие конструкции являются пористым материалом;

2). на границе материала и воздуха создана непроницаемая для воздуха и влаги стенка, необходимая для учета сопряженного конвективно- 
го и радиационного теплообмена в помещении. Поскольку через непроницаемые стенки потока массы нет, моделирование переноса массы паровоздушной смеси через непроницаемую стенку реализовано в виде специальных функций ANSYS-FLUENT, задаваемых на границах сопряжения. Функции обеспечивают равенство потоков в паровоздушной среде и материале ограждающей конструкции, а также отвечают за перенос массы через непроницаемую границу. Граничные условия со стороны воздушной прослойки записываются в виде равенства потоков со стороны стены и воздушной прослойки. Создание подобной функции не было найдено нигде в литературе, и это можно рассматривать как практическую новизну данной работы, поскольку, расширены границы использования пакета ANSYS-FLUENT для недоступного ранее класса задач - сопряженного тепломассопереноса между твердой поверхностью и паровоздушной средой с учетом радиационного и конвективного теплообмена.

Были приняты следующие допущения модели:

1) ограждающая конструкция принимается кусочно-однородной средой;

2) линейный характер изменения свойств (коэффициентов влагопроницаемости и паропроницаемости) от влажности.

Высота модели равняется 1 м. Теплопроводность материалов многослойной ограждающей конструкции принята изменяющейся от их влажности. Из-за отсутствия детальной информации о процессах тепловлагообмена в помещении, заданы граничные условия первого рода по теплу со стороны помещения - температура поверхности стены равна температуре в датчике 1 (рис. 1). Со стороны окружающей среды приняты граничные условия третьего рода - коэффициент конвективной теплоотдачи равный $20 \mathrm{BT} / \mathrm{M}^{2} \cdot \mathrm{C}$, а температура окружающей среды изменяется согласно измерениям, приведенным в [6-8]. Температура воздуха в воздушной прослойке также изменяется согласно данным [6-8], поскольку облицовка имеет зазоры для доступа воздуха из окружающей среды.

Аналогично, в качестве граничных условий по влаге со стороны помещения задана абсолютная влажность в датчике 1. Снаружи помещения заданы граничные условия третьего рода: коэффициент влагоотдачи $\beta=$ $=1 \cdot 10^{-8} \mathrm{\kappa} \Gamma /\left(\mathrm{M}^{2} \cdot \mathrm{c} \cdot\right.$ Па) $[10]$, а абсолютная влажность изменяется согласно измерениям в [6]. В качестве начальных условий принято тепловое состояние ограждающей конструкции в течении 2-х суток (это позволяет получить более достоверное начальное тепловое и влажностное распределение в ограждении).

Значения коэффициентов $k$ для каждого из слоев ограждающей конструкции идентифицировались по результатам имеющейся экспериментальной информации. Значения коэффициентов $k$ из (1) приведены в табл. 1. Идентификация вызвана недостатком исходных данных, изменением свойств материалов в процессе эксплуатации дома, влиянием многих факторов (например, «sun driven vapor transfer» - потоком пара, вызванным воздействием солнечной радиации) измерить которые невозможно.

Табл. 1. Идентифицированные значения коэффициента $k$ модели

\begin{tabular}{|c|l|c|}
\hline & \multicolumn{1}{|c|}{ Название материала } & Значение $k$ \\
\hline 1 & Гипсовая перегородка & $1 \cdot 10^{-18}$ \\
\hline 2 & Целлюлозная вата & $1 \cdot 10^{-16}$ \\
\hline 3 & ДСП & $1 \cdot 10^{14}$ \\
\hline 4 & Облицовка из лиственницы & $1 \cdot 10^{-18}$ \\
\hline
\end{tabular}

На рис. 2 приведены результаты сравнения расчетных и экспериментальных значений температур и абсолютных влажностей для датчиков 3 и 4 (см. рис. 1, б). Из рис. 2, $а$ и 2, $б$ видно, что наблюдается большее согласование по температурам, чем по влажности. Меньшую амплитуду колебаний расчетных температур можно объяснить тем, что в модели наружная обшивка 
из лиственницы представляет собой сплошной слой материала, в то время как в эксперименте обшивка имеет зазоры между дощечками. Эти зазоры приводят к тому, что ночью температура снижается в эксперименте больше, чем в модели, а днем эти зазоры позволяют проникать большему количеству тепла из-за солнечной радиации в воздушную прослойку. Результаты абсолютной влажности, приведенные на рис. 2, в и 2, г имеют большее различие. Возможной причиной большего различия результатов в датчике 4 по сравнению с датчиком 3, являются погрешности экспериментальных показаний из-за возмож-

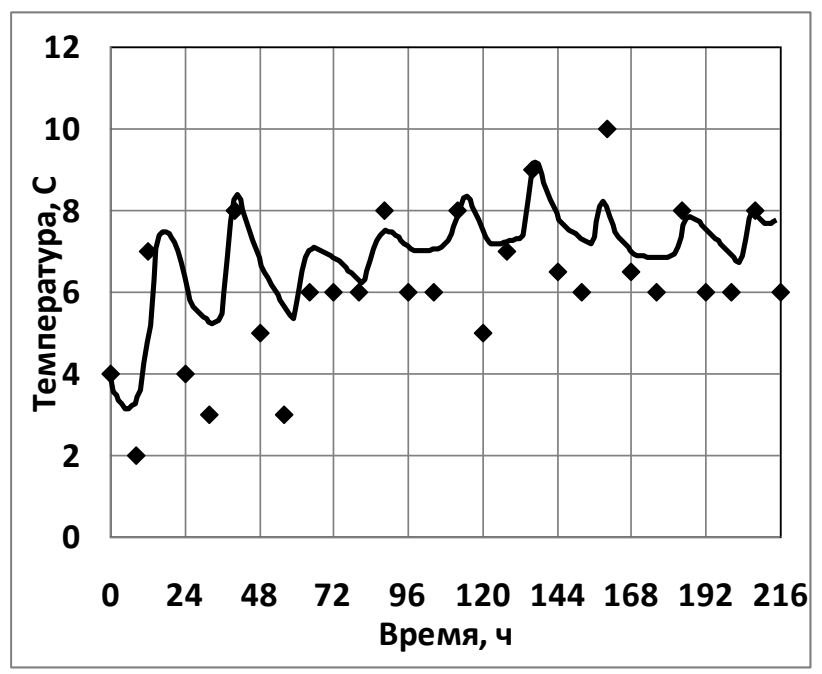

a)

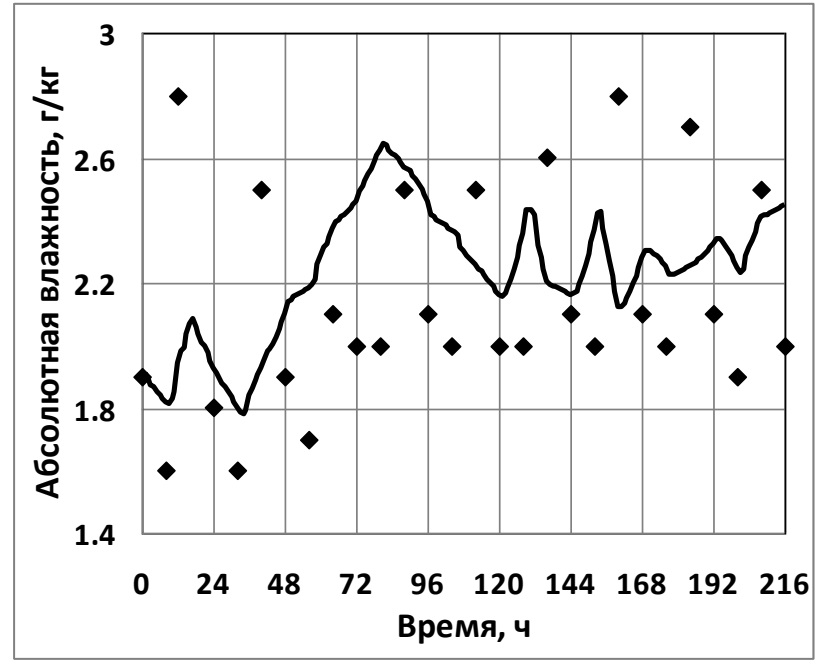

B) ного замерзания влаги в слое ДСП ночью, когда температура в слое падает ниже нуля, поскольку замерзание влаги в модели не учитывается. Большую амплитуду колебаний экспериментальных значений абсолютной влажности в датчиках можно также объяснить наличием зазором в слое обшивки. Эти зазоры интенсифицируют влагообмен на поверхности ДСП.

Среднее отклонение между расчетными и экспериментальными значениями температур равно $1,1{ }^{\circ} \mathrm{C}$, однако в некоторые моменты отклонение достигало $2,66{ }^{\circ} \mathrm{C}$. Среднее отклонение между расчетными и экспериментальными

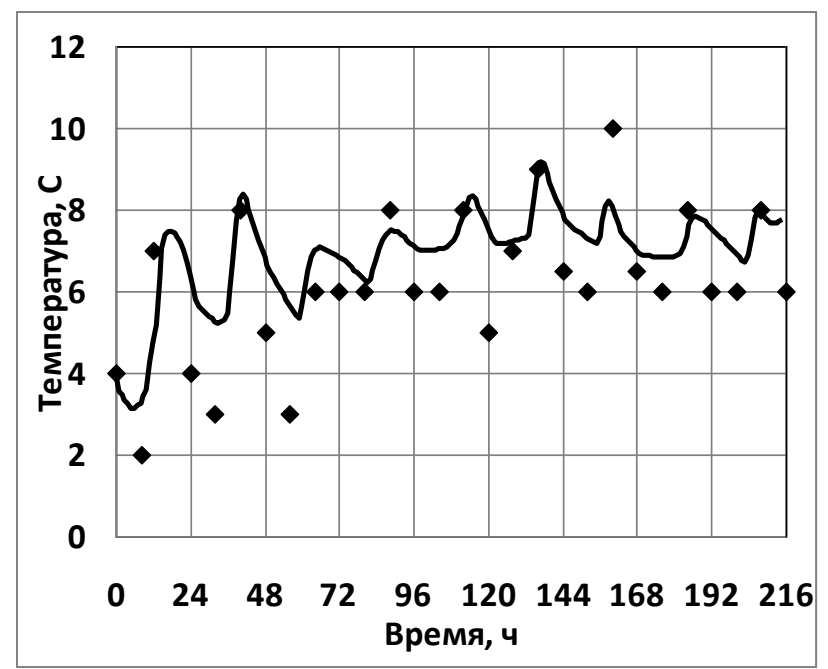

б)

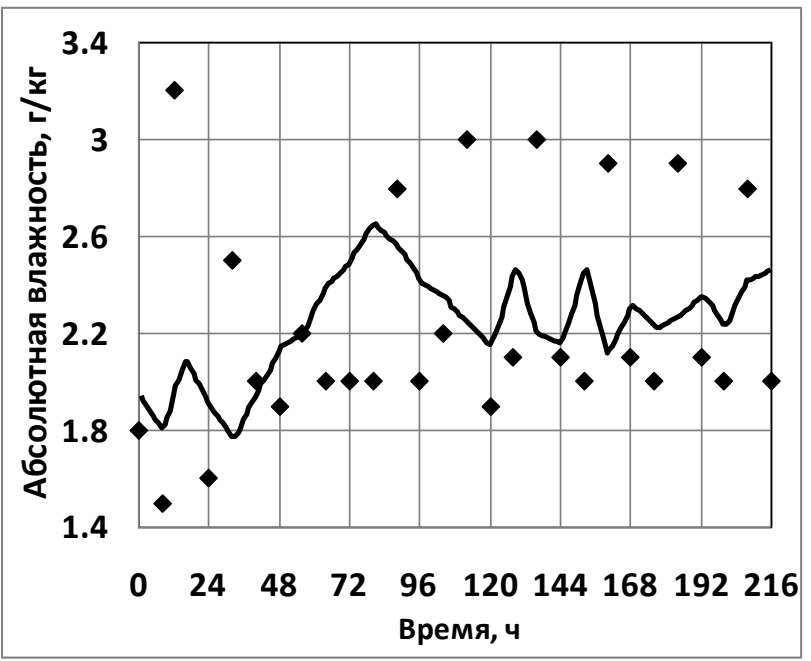

г)

Рис. 2. Сравнение результатов расчетных (сплошные линии) и экспериментальных (точки [6]) исследований. а, б- графики изменения температур в датчиках 3 (a) и 4 (б) по времени, в, г-графики изменения абсолютных влажностей в датчиках 3 (в) и 4 (2) по времени. 
значениями абсолютных влажностей равно 0,4 г/кг, однако в некоторые моменты отклонение достигало 1,2 г/кг.

Из результатов расчетов и экспериментов можно заметить что, несмотря на такое большое количество испаренной воды в помещении, в слое целлюлозной ваты, ограниченной с одной стороны паробарьером, а с другой стороны дождевым экраном, не наблюдается рост количества влаги в ходе эксперимента. Особенно это важно для строительства домов из дерева, особо подверженных сильному увлажнению.

Авторы проведенного эксперимента в [6,7] приводят сравнение полученных экспериментальных данных с их расчетами, проведенными в программе HAM-Tools. Ими была создана модель в сосредоточенными параметрами, где помещение было представлено 1 узлом, а стена 17 по толщине. Задавались постоянные значения коэффициентов конвективного и радиационного теплообмена в помещении, коэффициенты массоотдачи внутри и снаружи помещения. Остается неизвестным вопрос, как авторы моделировали воздушную прослойку, поскольку они упоминают о том, что ее моделирование позволило учесть двухмерные эффекты в тепломассопереносе. Авторы отмечают хорошее согласование результатов экспериментов и расчетов. Однако они же говорят о том, что несмотря на то, что средняя разница между экспериментальными и расчетными температурами равна $0,8{ }^{\circ} \mathrm{C}$, в некоторые моменты времени она достигала $3{ }^{\circ} \mathrm{C}$. Абсолютная влажность совпадала хуже. В качестве причин несовпадения авторы приводят возможные погрешности определения температуры окружающей среды (из-за интенсивной солнечной радиации); высокой скорости воздуха окружающей среды, что приводит к большей инфильтрации конструкции; а также такому явлению как «sun driven vapor transfer» - потоку пара, вызванному воздействием солнечной радиации.

Преимуществом разработанной модели является совместный учет всех механизмов тепловлагообмена в ограждающей конструкции, особенно в воздушном зазоре вентилируе-мого фасада.

Дальнейшие исследования будут направлены на учет многомерных эффектов тепловлагопере- носа, расчетов полностью сопряженного тепловлажностного режима помещения и его ограждающих конструкций. Будущая модель должна описывать увлажнение/осушение ограждающей конструкции в зависимости от влажности и температуры воздуха внутри помещения и окружающей среды в годовом цикле, а также рассчитывать образование конденсата в паровоздушной смеси при достижении температуры «точки росы».

\section{Выводы}

1. Создана модель сопряженного тепловлагопереноса между многослойными пористыми строительными материалами и паровоздушной средой через наружную ограждающую конструкцию с воздушной прослойкой. CFD-модель учитывает процессы диффузии паров и влаги в материалах слоев ограждающей конструкции.

2. Разработаны специальные функции, реализующие сопряженный тепловлагоперенос в ANSYS-FLUENT. С помощью этих функций расширены границы использования программы ANSYS-FLUENT для решения задач сопряженного тепловлагопереноса между твердой поверхностью и паровоздушной средой с учетом радиационного и конвективного теплообмена.

3. Приведено сравнение результатов расчетов с экспериментальными данными натурного эксперимента в г. Гренобль. Анализ показал их хорошее согласование.

\section{ЛИТЕРАТУРА}

1. ANSYS FLUENT. Theory Guide. Realise 14.0. $-2011 .-862 \mathrm{c}$.

2. Steeman HJ, Janssens A, De Paepe M. CFD modelling of HAM transport in buildings: The importance of local indoor climate // Annex 41 meeting, UG Oct 2005 Paper A41-T1-B-05-8.- 2006.

3. Mortensen L. H., Woloszyn M., Rode C., Peuhkuri R. Investigation of Microclimate by CFD Modeling of Moisture Interactions between Air and Constructions // Journal of Building Physics. - 2007. - Vol. 30. - C. 279 - 315.

4. Belleghem, M.V., Steeman, M., Willockx, A., Janssens, A., De Paepe, M. Benchmark experiments for moisture transfer modelling in air and porous materials // Building and Environment. - 2011. - 
Vol. 46. - C. $884-898$.

5. Круковский П.Г., Полубинский А.С., Тадля О.Ю. Особенностимоделирования со-пряженного тепловлагопереноса через газобетонную ограждающую конструкцию // Про-мышленная теплотехника. - 2015. - Т. 37, №1. - С. 32 - 44.

6. Labat M. Chaleur - Humidité - Air dans les maisons à ossature bois. Expérimentation et modélisation // Ph.D. Thesis, L'institut National Des Sciences Appliquees De Lyon, France. - 2012. $180 \mathrm{c}$.

7. Labat M., Woloszyn M., Garnier G., Piot A., Roux J.-J. Simulation of coupled heat, air and moisture transfers in an experimental house exposed to natural climate // Proceedings of BS2013: 13th Conference of International Building Performance Simulation Association, Chambéry, France, August 26-28. - 2013. - C. $2898-2906$.
8. Spitz C., Woloszyn M., Buhé C., Labat M. Simulating combined heat and moisture transfer with Energyplus: an uncertainty study and comparison with experimental data // Proceedings of BS2013: 13th Conference of International Building Performance Simulation Association, Chambéry, France, August 26-28. - 2013. - C. $668-676$.

9. Piot $A$. Hygrothermique du bâtiment : expérimentation sur une maison à ossature bois en conditions climatiques naturelles et modélisation numérique // Ph.D. Thèse, Institut National des Sciences Appliquées de Lyon, France. - 2009. $174 \mathrm{c}$.

10. Künzel H.M. Simultaneous Heat and Moisture Transfer in Building Components: Oneand Two dimensional calculation using simple parameters // Ph.D. Thesis, University of Stuttgart, Germany. - 1995. - 65 c. 
CFD-MODELING OF CONJUGATE COUPLED HEAT AND MOISTURE

BETWEEN THE POROUS BUILDING MATERIALS AND STEAM-AIR ENVIRONMENT

Krukovsky P. G., Polubinskiy A.S., Tadlia O.Y., Kovalenko V.N.

Institute of Engineering Thermophysics of the National Academy of Sciences of Ukraine, vul. Zhelyabova, 2a, Kyiv-57, 03057, Ukraine

A CFD-model to simulate the conjugate heat and moisture transfer between the building envelope surface and internal air-steam-medium layer with radiation and convective heat transfer. was developed with ANSYS-FLUENT software. The conjugate heat and moisture transfer is realized using of specially created function, that expanded calculated capabilities of ANSYS-FLUENT software. Obtained temperature and absolute humidity distributions with sufficient accuracy correspond to the experimental data.

References 10, fig. 2, tabl. 1.

Key words: coupled heat and moisture transfer, air gap, CFD-simulation, ANSYS FLUENT.

1. ANSYS FLUENT. Theory Guide. Realise 14.0. - 2011. - 862 c.

2. Steeman HJ, Janssens A, De Paepe M. CFD modelling of HAM transport in buildings: The importance of local indoor climate // Annex 41 meeting, UG Oct 2005 Paper A41-T1-B-05-8.-2006.

3. Mortensen L. H., Woloszyn M., Rode C., Peuhkuri R. Investigation of Microclimate by CFD Modeling of Moisture Interactions between Air and Constructions // Journal of Building Physics. - 2007. - Vol. 30. - P. 279 -315.
4. Belleghem, M.V., Steeman, M., Willockx, A., Janssens, A., De Paepe, M. Benchmark experiments for moisture transfer modelling in air and porous materials // Building and Environment. -2011. - Vol. 46. - P. $884-898$.

5. Krukovsky P. G., Polubinskiy A.S., Tadlia O.Y., Kovalenko V.N. CFD-simulation of cou-pled vapor and moisture transfer in porous building materials // Promyshlennaya teplotekhnika. - 2015. - T. 37, №1. - P. 32 - 44.

6. Labat M. Chaleur - Humidité - Air dans les maisons à ossature bois. Expérimentation et modélisation // Ph.D. Thesis, L'institut National Des Sciences Appliquees De Lyon, France. - 2012. $180 \mathrm{p}$.

7. Labat M., Woloszyn M., Garnier G., Piot A., Roux J.-J. Simulation of coupled heat, air and moisture transfers in an Experimental house exposed to natural climate // Proceedings of BS2013: 13th Conference of International Building Performance Simulation Association, Chambéry, France, August 26-28. - 2013. - P. 2898 - 2906.

8. Spitz C., Woloszyn M., Buhé C., Labat M. Simulating combined heat and moisture transfer with energyplus: an uncertainty study and comparison with experimental data // Proceedings of BS2013: 13th Conference of International Building Performance Simulation Association, Chambéry, France, August 26-28. - 2013. - P. 668 - 676.

9. Piot A. Hygrothermique du bâtiment : expérimentation sur une maison à ossature bois en conditions climatiques naturelles et modélisation numérique // Ph.D. Thèse, Institut National des Sciences Appliquées de Lyon, France. - 2009. $174 \mathrm{p}$.

10. Künzel H.M. Simultaneous Heat and Moisture Transfer in Building Components: One- and Two dimensional calculation using simple parameters // Ph.D. Thesis, University of Stuttgart, Germany. 1995. $-65 \mathrm{p}$. 